\title{
The Analysis of three Case Studies as a guide to the Development of Pedagogy in Engineering Design Education
}

\author{
Brian Burns \\ Associate Professor, School of Industrial Design \\ Carleton University \\ brian_burns_eng@carleton.ca
}

\begin{abstract}
The Case Study has become a pedagogical vehicle of choice in helping engineering students to gain perspective on the multidisciplinary realities of design. What once were termed 'war stories' have evolved to a level where case studies are available and downloadable on all manner of topics. For the fundamental knowledge-based issues of engineering, example questions have commonly been created to help the student manoeuvre through all manner of possible combinations of application. The case study is not however fabricated, and relies on the reporting and documentation of a real design or engineering product development. In recent years many of these case studies have been related to ethics and communication, but very few have been related to ongoing product development and issues of Industrial Design. This is not surprising since the creation of such case studies is time consuming, and design is often a 'messy' process in which few companies would be keen to expose their failures along the way. Nevertheless case studies are a vital part of Engineering Design education and offer excellent potential for the development of the pedagogy vital to the dynamic formulation of Engineering Design Education. This paper references three design projects undertaken professionally by the author as an Industrial Designer working with predominantly engineering based companies. The aim is to identify critical aspects of these projects that could be used as lessons, perhaps, but not necessarily, as case studies, but to be incorporated into engineering design education.
\end{abstract}

\section{Introduction}

Like most forms of education, Engineering Design offers specific skill and knowledge bases which it then attempts to put into a broader perspective to reflect the 'real world' through examples and case studies - some would call this the development of tools and maps. Early knowledge of engineering principles was learned through experience, which quickly became theory while lecturers and professors offered what were often termed 'war stories', usually based on their own personal experience, to help put theory into applicable perspective for their students. Alongside this approach came the development of example questions to illustrate varying scenarios. The education of engineers has, as a consequence, become increasingly theoretical and easier to teach as a consequence. Gone are tables and slide rules and 'rules of thumb', as computer simulation and software make design more precise and far quicker. At the same time the students have become more removed from basic understanding of engineering fundamentals. This is not seen as the fault of engineering education, but more a reflection of the separation that now exists for everyone as we are increasingly removed from 'tinkering' with the objects that surround us.

The following poem written by the Reverend John Pierpoint and published in 1857 was used by Henry Petroski in his book 'Success through Failure'[1] to illustrate the growing gap -

'His pocket-knife to the young whittler brings A growing knowledge of material things.

Thus, by his genius and his jack-knife driven, Ere long he'll solve you any problem given; Make any gimcrack, musical or mute, A plough, a coach, an organ or a flute; Make you a locomotive or a clock; Cut a canal or build a floating dock; Make anything, in short, for sea or shore, From a child's rattle to a seventy-four; Make it, said I? Ay, when he undertakes it, He'll make the thing and the machine that makes it.'

Perhaps this is more illustrative of what many might believe to be the birth of the Golden Age of Engineering. 
There is no doubt, however, that the knowledge base required in a sound engineering education has grown considerably. This has led to the formation of many specialised new schools of engineering; from systems to electronics and from medical to environmental. Alongside this comes the increasing awareness of the multidisciplinary nature of engineering design with other practices and the need for appropriate communication.[2] As a result programs struggle to include the growing body of knowledge while students become more specialised. Perhaps this is epitomised by the increasing availability of case studies on matters such as ethics and communication itself.

For theoretical work, we are well served by computing technology, but for design there exists a persistent need for experience and grounding.

It is important at this point to make a significant separation. Design can be understood to be the creation of a new 'something' similar to the 'something' that went before. However, more often than not, particularly in fast changing technologies, the next 'something' is likely to be vastly different to its predecessor. In such situations case studies are vital to illustrate what are often seen as 'messy processes' and how they deal with failure, the unforeseen, human variables, and the interconnectedness of disciplines in engineering design and development.

Henry Petroski espouses the importance of 'Learning through Failure' in his book of the same name [3], yet many companies are reluctant to admit to failure along the way - hindsight is $20-20$, and we do not want to look 'bad' to our competitors or our share-holders. It becomes difficult then to find design case studies that freely document the mishaps and wrong turns of designing.

If such case studies were to exist, and there are some good examples, then their specificity makes them less useful in a broader educational context, and in many fast changing fields of technology, their significance quickly dates.

The challenge is to help students of engineering design to learn how to use the tools of designing by building awareness of the complexities of design reality, without reliance on specific case studies, which may or may not exist or be specifically relevant.

\section{The Search for Design Knowledge}

While it would be a useful exercise to assemble a range of case studies to distil from them the lessons that need to be learned, for this paper a different strategy has been adopted.

During the past few years the author has worked as an industrial designer with a range of predominantly engineering based companies in the ongoing development of their products. Three have been selected for the purpose of this paper. In each case it would be highly unlikely that they would have had the time or the inclination to prepare a publically available case study to reflect their design development process. Thus, for the purpose of this paper, they have been treated anonymously, with no inappropriate reference to intellectual property or their identity.

Each company was at a different stage of product development but each product was founded on successfully proven engineering work. The essence of their product development was sound, and they exist as small to mid-sized companies in which many engineers might find themselves after graduation. The challenges in each case were different, but were concerned with engineering design development and the resulting products. Thus the information concerning the companies is deliberately vague, with the specifics focused on the process and the lessons learned.

\subsection{Company A - Telephony}

The company had been very successful with a small injection moulded plastic cased telephony device for office use. Manufacture was predominantly overseas, and it was felt that there might be some small technological changes in the near future. It was felt that the image of the product could no longer be 'visually quiet' with a need to offer better looks, application, variable utility, and 'updatedability'; perhaps as a product sold under various brand identities. There was clearly a need to retain and maintain current clients and support existing products in the marketplace, while establishing a plan of development for the next 5 to 10 years. My task was to help them better understand their own needs and to help them connect with an Industrial Design company to undertake the appropriate design work in line with their development objectives.

\subsection{Company B - Water Quality}

This could truly be considered to be a start-up company, and was based on well proven chemical engineering. Their product is able to detect water impurities of all types far quicker than existing methods and at a more defined level of concentration. My task was to help manifest this technology into devices that could be used in the field for appropriate testing and ultimately as saleable devices. 


\subsection{Company C - Fuel Testing}

This company has for several years built and sold a piece of equipment to test the performance of specific fuels throughout the World. The success and acceptance of the existing product and the growing global interest in fuel quality and performance specifications has led to the need for a remodelling of the existing product to match recent technologic upgrades and to make it easier to use and calibrate by a less skilled operator. My task was to help them take a fresh look at their existing product and to help them develop the concept for ease of use alongside future upgrades.

\section{The Role of Industrial Design}

The International Congress of Societies of Industrial Design defines Industrial Design as 'a creative activity whose aim is to establish the multi-faceted qualities of objects, processes, services and their systems in whole life cycles. Therefore, design is the central factor of innovative humanization of technologies and the crucial factor of cultural and economic exchange'.

For many this can be interpreted as a means to create the right product at the right price at the right time appropriately using the engineering principles on which the product is founded. When the marriage works everyone is happy, but unfortunately there exists a lack of appreciation of the capabilities of the people on both sides of the imaginary fence between the two disciplines. For some designers a disappointing challenge may well result in the designers feeling that they were engaged far too late in the process and that all they could do was to try 'to put lipstick on a pig'.

This paper will not attempt to establish what industrial designers need to know about engineers, but will focus on what engineers can learn to improve their relationship with industrial designers, and as a consequence, any other discipline that the world is plotting for them to work with in the future.

Specifically, industrial design is concerned with the logic and functionality of the product itself, and is concerned with ergonomics and the user, manufacturability, shipping and transportation, safety, repair, brand, maintenance, upgradability, the market window, marketing, and to be able to put all of these attributes into a form that will be inviting to customers and users alike. All while maintaining the company image and ensuring its place in the market in the years to come......and that is without consideration for the growing concerns for eco-sustainability and resource efficiency.
For an engineering company to approach an industrial design company there is the need for communication and an appropriate understanding of what needs to be done. The best results come from a well communicated transition, and to a large extent case studies have grown to be used to help facilitate this process. This paper is derived from an analysis of the design tasks undertaken in helping three companies take their next steps in product development.

\section{The Analysis of the Design Tasks}

As more and more computing technology becomes the common tool of more and more disciplines there no longer seems to be a time for one task to end and one to begin. Work goes on in parallel; independently, but reliant on compatible outcomes. Software is becoming the facilitator of much of this work at a high level, but in the early development stages this is not so easy to accomplish.

The following four sections offer a synthesis of the specific knowledge that the author offered to facilitate the companies design development objectives. Because there is overlap, they are not directed to any one specific company, but were found to be significant to each.

\subsection{Ergonomics and Usability}

In all three cases considerable time was spent in helping the engineering designers to become aware of the needs of their product's users. It became clear that there is a need for engineers to understand that many users of equipment do not have to, or want to, understand how a product works to be able to use it appropriately. There also seemed to be something of a lack of appreciation of appropriate user comfort. This is not surprising since many engineered products start out as successful devices using off-the-shelf switches, levers and controls, and it is also a large leap of understanding to the simple smooth devices that populate our homes, kitchens and communication devices.

The saying suggests that familiarity breeds contempt, but for the engineering designer it appears to be a difficult step to understand the innocent user, and the first time that they will encounter a new device. As a consequence, in all three companies, exercises were undertaken with focus groups, members of the company in non-engineering roles, and by simple comparison with competitive more mature products, to establish the appropriate criteria for issues of installation, operation, visibility, 
appropriate comfort levels, control, repeatability, maintenance and repair. Valuable lessons were learned very early in the process by simply understanding what was possible and desirable. In one case it helped to confine the functionality when it became clear that certain existing attributes were unnecessary.

\subsection{Quantity and the Path to Product Maturity}

Most engineers learn that the fundamental key to engineering success lies in functionality and reliability, and this where the dominant part of their efforts is focused. As a reflection, most products start out as one-off devices - 'breadboard models' - that work. Quite commonly there is an immediate need to make a few products. Commonly this is 2 or 3 , which requires off the shelf parts or some advanced modelling and basic fabrication. With such devices proof of concept is established, and in many cases the work of the design engineer moves on. In large markets and in large companies there exists specialist skills to take care of issues of manufacture, but for many smaller companies, the quantity of manufacture will be initially quite limited. Each of the three companies referred to here had products at a different stage of development - from basic off-the-shelf fabrication to injection moulded components. The path to product maturity is a complex one where decisions based on quantity can have major effects on business success, cash flow and the maintenance of customers. The following table illustrates fairly simply this path;

The Invention - The seed of most products begins with an invention or technological breakthrough. Products at this stage of development often become a toy for the rich, an expensive luxury, or a hope for the company's future. The early automobile is an example. In this phase the user is likely to tinker with the product, which may well be far from reliable- akin to the engineer's breadboard model.

Reliable Prototype/Batch Product - Reliability and safety are improved as short run products are made. At this point the product may well exist in a social vacuum, without infrastructural support. There may well be the beginning of competition, with rival companies quick to outdo the other. Patents are developed as new products are hurried to market. The field of robotics offers a contemporary example.

First Generation Product - The market size and hence the production run increases, enabling more sophisticated manufacturing processes to be utilised. The form tends to be reasonably indicative of how the product functions and relatively easy for the user to understand. Changes, particularly technological change, may affect product life-span; in the case of the personal computer this includes both hardware and software.

Integrated Product - As reasonable levels of safety and reliability are established, the product becomes available in larger quantities and more often considered a necessity. Its form and image become more integrated as users are allowed to be more ignorant of how it functions through a combination of industry standards, voluntary guidelines and consumer law. Interaction levels are then defined, both humanized and non-humanized (what can be touched and what not). The product's infrastructure begins to form and life-span options can now be better evaluated. International standards may be brought about by the major companies.

Mature Product - The product's infrastructure is established. Maintenance, control and standards are appraised and organized. Products made by different companies start to look the same, and the norms of quality, longevity, performance and manufacture evolve through industry standards, voluntary guidelines and consumer law.

It is fairly easy to consider the evolution of the car or the telephone in relation to the steps outlined above. In the evolution of other products the steps are apparently jumped, merged or even revisited. However, for engineering design the importance of understanding the potential pitfalls and impacts of the path from quantities of 2 or 3 to 100,000 is important.

\section{3 'Looking Cool' and Modelling}

When do products need to start to look 'cool'? In some cases it is because of increased market size and the need for the user to be safe and confident in operating the device, and in some cases it is simply a need to stand out from the competition. For either reason there is usually a need for the product to 'look cool'. Sadly this may be a leftover from the days when industrial designers were seen simply as those people who could put a sleek plastic case around a technological core. This may still be true with many products. However, expecting an engineer to know how to do this is unnecessary - that is why we have specialists, but it certainly would be useful if young engineering designers were to become more aware of product typography.

In cases where a new form or appearance is required the ability for the engineers to able to envisage potential solutions is important. The ability to mock up a form in full size cardboard always seems to prove invaluable. While such a model is not functional it 
helps resolve important issues of use, size, general appearance, maintenance, access and even assembly. This is a simple process which can be readily taken into graphic software for more accurate visual detailing.

As for 'looking cool', experience shows that design engineers have a certain sensitivity to the particular market their product competes in. This may be through brochures and visits to trade shows, and working with the engineers to help them establish what they feel 'cool' to be, has proven very useful.

Simply by using a combination of competitive brochure material and modelling full-size in corrugated cardboard, it is reasonably easy to quickly help the visualisation process and develop some consensus as what the desired look and feel might be.

\subsection{Language of Interdisciplinary Communication}

Industrial designers listen to a briefing from an engineer in a very distinct way. This can be best explained as an attempt to mirror the outputs of the device. This would relate, for example, to issues of heat output - should there be ventilation or can it be touched, or will something melt? All performance criteria are evaluated as an effect, rather than to understand the cause, which then must be designed around. The same can be said for the needs of the packaging engineer, the publicist, the advertising executive, the marketing manager, and the materials supplier. All have their particular way of listening and comprehending.

The three company projects involved engineering and science that required specialised knowledge. It became essential then to be able to interpret the implications of the function of the product in question to enable an appropriate formal solution. Where there is interdisciplinary development, there will be a need for specialists to communicate and to learn respect the challenges of their counterparts.

\section{The Formulation of Pedagogical Needs.}

While it would be foolish to suggest that the above list identifies all the issues that a good design engineer needs to know about design in the real world, it clearly highlights the existence of issues that could be beneficially recognised pedagogically. To help the process, the above four sections will be evaluated from an educational perspective, to determine how they might be incorporated into an engineering design program.

Ergonomics and Usability - While this is a core subject in industrial design, ergonomics and anthropometrics are not a major part of most engineering programs. When dealt with at all, it is often in relation to a particular device to fit with the human body, a prosthetic for example, and as such is dealt with statically and leaning heavily on anthropometric data. It would seem beneficial to incorporate some measure of ergonomic and anthropometric study perhaps under its other popular title, Human Factors. This could certainly be undertaken using case studies, lectures, and projects, and would at least lead to valuable awareness on the part of the student.

Quantity and the Path to Product Maturity here a notion of historic context would seem essential, with a review of products, their invention, and their evolution. Once again the automobile and the telephone offer obvious backdrops, but the same can be said for all engineering development that started its life as a concept in a lab, and ultimately became a success in the marketplace. The products of the Dyson company would perhaps serve as a current example. This could undertaken in part be as a case study, but would not need to be, and could easily be lectured or studied on an individual basis; which in itself could lead to a useful collection for use by future students.

'Looking Cool' and Model Making Engineering students historically enjoy making things that work, and there are a range of vehicular and capstone projects in universities that prove it. At the heart of these projects lies functionality - making something work. For the industrial designer, however, form and colour lies at the core of design thinking. Perhaps this is the key differentiator between industrial design and engineering design. Nevertheless, there is much to be learned from model making beyond pure functionality. It might then be opportune to encourage engineering students to experiment in more immediate materials, such as cardboard for example. This could even be undertaken as part of an ergonomic/user centred design exercise.

In trying to make things 'look cool' a lecture course or a study of 'why things look cool' might be a useful opportunity to raise awareness, and help students find words that aree more explicit than simply 'looking cool' (no industrial designer would be allowed to simply say 'it looks cool'- there would be an expectation to explain why.)

Language of Interdisciplinary Communication The awareness that this pedagogical need identifies can probably best be addressed by means of interdisciplinary study or projects. It would be foolish to expect any single discipline to be the master of all disciplines, and it would be equally foolish to expect that only engineering has this need. This area of awareness reinforces the need for interdisciplinary 
study at a senior level; in third and fourth years At this point the students are more aware of the need for such communication, which would then help them benefit from the opportunity.

\section{The Role of Case Studies and Projects}

When a student is exposed to a case study there is an immediate sense of reality. The learning challenges faced by the student on a daily basis on the computer, using text books and listening in lectures, suddenly become grounded in a reality; with the implied aspiration that, 'you too could do this work in the future'. There is no doubt of the merits of case studies in this role. However, there cannot always be the perfect case study available to excite students, and in many cases the case study is merely a conduit. The key is in raising awareness, and there are many other ways in which this can be achieved.

The key, it would seem lies in the balance between example and reality. What links them is the building of an awareness of the issues that should form part of an engineer's education in design.

The examples used in this exercise are not untypical, nor could they be felt to be all encompassing. However this exercise, based on real design experience has led to the identification of what are seen to be benefits in design engineering education. Case Studies appear to be one means to aid learning. Here they have been used at arm's length for the purpose of establishing awareness of what needs to be incorporated; this may be achieved through case studies, but could just as well employ examples in text books, specially designed projects, research projects and even by extrapolation from co-op experiences.

\section{In Conclusion}

Barriers between disciplines exist for many reasons, but in most cases they are a hindrance; particularly to engineering design development. Experience and literature speaks of these failures to communicate and how to overcome them, but the solution lies not just in better examples or simply more case studies. The solution lies in understanding the pedagogy of learning in engineering design. While all case studies are interesting, they may or may not be pedagogically relevant. To improve education in engineering design we need to embrace the disciplinary differences, and raise awareness; and to do so in a pedagogically creative way. The students and the future of Engineering Design demand it.

\section{References}

[1] H. Petroski, Success through Failure, Princeton University Press, Princeton, 2006.

[2] C. Matthews, Case Studies in Engineering Design, Arnold, London, 1998.

[3] H. Petroski, ibid. 